the apparent resistance of 'immature' flukes or which is the most important.

The results in laboratory animals with this compound were so promising that it is now being extensively evaluated in sheep and cattle under a variety of farm conditions. Preliminary reports from a number of workers indicate that it may be of considerable value and, accordingly, it is being made generally available by Imperial Chemical Industries, Ltd., under the brand name of 'Zanil'.

\section{A. W. Broome}

W. G. M. Jones

Imperial Chemical Industries, Ltd.

Pharmaceuticals Division,

Research Department,

Alderley Park, Macclesfield, Cheshire.

\section{HAEMATOLOGY}

\section{Strain and Sex Dependency of Pre-albumin in Mice}

THE composition of the pre-albumin fraction in the serum of several species is known to be a hereditary characteristic $^{1-5}$, but sex dependency has not as yet been described.

We used Smithies'6 horizontal technique of starch-gel electrophoresis in a discontinuous buffer system (tris, citrate, borate/borate, $p H \quad 8 \cdot 5$ ). In this way the prealbumin in serum of mice was separated into three clearly distinct components $\left(\mathrm{PA}_{1}-\mathrm{PA}_{2}-\mathrm{PA}_{3}\right)$. We were not able to express our data on pre-albumin concentration in $\mathrm{mg} / \mathrm{ml}$, since pure PA was not available to us as a reference. Instead, measurements were taken with a densitometer after we had stained our electrophoretograms with amido black $10 B$.

Seven inbred strains of mice were investigated: $A K R$, $B A L B / c^{+}, C B A, C 57 B L, C_{3} H, C O_{13}$ and $R F$. Groups consisting of 25-30 males of each strain were examined. Fig. 1 shows the electrophoretic pattern of serum in the different strains of mice. $\mathrm{PA}_{2}$ is present only in the $A K R$, $B A L B / c^{+}$and $R F$ strains and is not observed in the others.

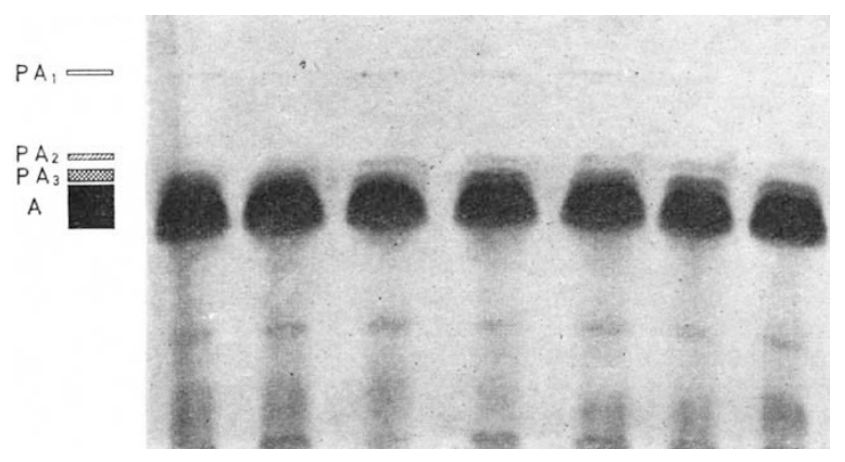

Fig. 1. Starch-gel electrophoresis of the serum of different strains of maje mice. From left to right: $C 57 B L, C O_{13}, R F, A K R, C_{3} H, B A L B / c^{+}$ and $C B A$

The electrophoretic pattern of female mice is sig. nificantly different from that of the males. As Table 1 shows, $\mathrm{PA}_{1}$ is detectable only in male mice and $\mathrm{PA}_{2}$ and

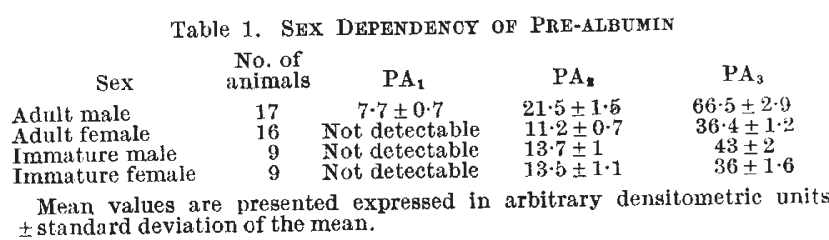

$\mathrm{PA}_{3}$ are significantly lower in females (55 per cent and 52 per cent for $\mathrm{PA}_{2}$ and $\mathrm{PA}_{3}$, respectively, of that of male mice).

No significant differences were detected in the electrophoretic patterns of immature 4-week-old male and female mice, but they are different from adult females.

We are at present investigating the influence of sex hormones on the concentration of pre-albumin in the serum of mice.

This work was supported by Fonds de la Recherche Scientifique Fondamentale Collective.

A. Reuter

Department of Radiobiology,

Centre d'Etude de l'Energie Nucléaire, Mol, Belgium.

${ }^{1}$ Blumberg, B. S., and Robbins, J., Endocrinology, 67, 368 (1960).

${ }^{2}$ Kristjansson, F. K., Genetics, 48, 1059 (1963).

${ }^{3}$ Shreffler, D. C., Genetics, 49, 630 (1064).

* Miller, J. B., Nature, 200, 810 (1963).

${ }^{5}$ Fagerhol, M. K., and Broend, M., Science, 149, 986 (1965).

${ }^{6}$ Smithies, O., Biochem. $J ., 61,629$ (1955).

\section{Aggregation of Human Platelets by Dextrans}

DURING the course of an investigation into the offect of dextrans on platelet aggregation induced by adenosine diphosphate, it was noted that the addition of dextrans of various molecular weights to platelet-rich citrated human plasma in vitro resulted in a fall in the optical density of the plasma. This effect has been examined using a turbidimetric method ${ }^{1}$, and also phase-contrast microscopy.

Blood was obtained from normal volunteers by atraumatic venepuncture using siliconized S.G. 20 needles, plastic tubes containing 3.8 per cent sodium citrate, one part citrate to nine parts blood, and was centrifuged at $190 \mathrm{~g}$ for $10 \mathrm{~min}$ to give platelet-rich citrated plasma (PRCP) which was used within $3 \mathrm{~h}$. 2 -ml. portions of PRCP were placed in siliconized glass cuvettes and were stirred with polythene-covered magnetic stirrers. The optical density of the PRCP was measured at room temperature in an EEL titrometer using a red filter (608). 20 per cent solutions of dextrans of various molecular weights were prepared in 0.895 per cent sodium chloride.

The addition of dextran to a final concentration of more than 0.5 per cent to PRCP results in an immediate optical clearing effect larger than the dilutional fall in optical density, produced either by the addition of similar volumes of isotonic sodium chloride to PRCP, or of dextran to platelet-free plasma. Resuspension of the isolated platelet button in the platelet-free plasma restores the effect just described. The effect is also seen after the addition of dextrans to suspensions of washed platelets in a saline-tris hydrochloride buffer solution.

Table 1. Mean Percentage Fale in Optical Density after the ADDITION $O H^{\circ} 0.2$ ML. OF 20 PER CENT SOLUTIONS OF DEXTRANS OF VARIOUS MEAN MOLECULAR WEIGHTS IN ISOTONIC SAline, AND OF 0.2 ML. SALINE ALONE TO $2 \cdot 0$-ML. PORTIONS OF PRCP Additive No. of exps. Mean $\%$ fall in O.L.

$\begin{array}{lcc} & \text { No. of exps. } & \text { Mean } \\ D 10 \dagger & 22 & 18 \cdot 8 \\ D 20 & 19 & 19 \cdot 0 \\ D 40 & 21 & 20 \cdot 1 \\ D 80 & 20 & 21 \cdot 8 \\ D 110 & 19 & 20 \cdot 2 \\ D 150 & 19 & 16 \cdot 6 \\ D 250 & 21 & 16 \cdot 6 \\ D 500 & 22 & 17.0 \\ \text { Sodium chloride } 0.895 \% & 17 & 8.1\end{array}$

* Final dextran concentration 1.82 per cent. mean molecular weight of 20,000 , ete.

Examination of small aliquots of PRCP and of platelet suspensions before and after the addition of dextrans, using phase-contrast microscopy and siliconized microscope slides and coverslips, confirms that dextrans produce platelet aggregation in vitro (Figs. 1 and 2). The degree of platelet aggregation, according to changes in optical 